\title{
EFEITOS DA PARTICIPAÇÃO DE CONSÓRCIOS NOS LANCES E DESÁGIOS EM LEILÕES DE TRANSMISSÃO DE ENERGIA ELÉTRICA NO BRASIL
}

\author{
Nayara Peneda Tozei * \\ Wilson da CRUZ Vieira ${ }^{\dagger}$ \\ Leonardo Bornacki de Mattos $\ddagger$
}

\begin{abstract}
Resumo
Este trabalho objetivou avaliar os efeitos da participação de consórcios nos lances e deságios em leilões de transmissão de energia elétrica realizados no Brasil, no período de 2000 a 2011. Foram considerados modelos empilhados com todos os lances (606 observações) e de séries temporais com os lances vencedores (148 observações). Esses modelos foram estimados pelo método dos Mínimos Quadrados Ordinários e por Efeito de Tratamento. Os resultados indicaram que os consórcios foram menos competitivos do que as firmas individuais, pois forneceram, na média, lances maiores e deságios menores. O número de participantes, como esperado, teve efeito competitivo sobre lances e deságios. A receita, por sua vez, esteve positivamente relacionada aos lances, mas não impactou os deságios de forma significativa.
\end{abstract}

Palavras-chave: Leilões, energia elétrica, métodos econométricos, Brasil.

\begin{abstract}
This work aimed to evaluate the effects of consortia participation on bids and discounts in electric power transmission auctions held in Brazil from 2000 to 2011. We considered pooled models with all bids ( 606 observations) and time series models with the winning bids (148 observations). These models were estimated by Ordinary Least Squares (OLS) and treatment effect. The results indicated that consortia were less competitive than individual firms, since they provided, on average, higher bids and lower discounts. The number of participants, as expected, had competitive effect on bids and discounts. The revenue, in turn, was positively related to bids, but didn't have significant impact on discounts.
\end{abstract}

Keywords: Auctions, electricity, econometric methods, Brazil.

JEL classification: D44, C21, C22, C26

DOI: http://dx.doi .org/10.1590/1413-8050/ea481

\footnotetext{
*Universidade Federal de Juiz de Fora. E-mail: nayara.tozei@ufjf.edu.br

† Universidade Federal de Viçosa. E-mail: wvieira@ufv.br

‡ Universidade Federal de Viçosa. E-mail: lbmattos@ufv.br
} 


\section{Introdução}

Na década de 1980, o setor elétrico não contribuía para o crescimento econômico do país, pois não tinha condições de atender adequadamente o aumento da demanda por eletricidade decorrente do crescimento demográfico e da expansão do parque produtivo. Nesse período, o Estado não conseguia financiar a expansão de todas as instalações necessárias. Para tentar solucionar os problemas, foi necessário atrair investidores privados para o mercado (IPEA 2010). Os segmentos do setor foram então separados e foi incentivada a competição na geração e comercialização. Nas redes de transporte (transmissão e distribuição), por outro lado, o monopólio foi preservado, concedido a empresas vencedoras de um processo de licitação.

Na transmissão, as licitações, que tiveram início em 1999, permitiram grande ampliação da capacidade instalada do setor (ANEEL 2010). Os leilões, iniciados em 2000, são de formato híbrido, similar ao leilão de venda estudado por Dutra \& Menezes (2002) e ao aplicado nos leilões de espectro de telefonia (anglo-holandês) ${ }^{1}$, mas em forma reversa. Em um primeiro estágio, o leilão é do tipo selado, com as propostas dadas em envelopes fechados. Todos os lances precisam ser iguais ou inferiores ao valor máximo permitido em edital, e o vencedor é aquele com a menor proposta. O segundo estágio, que ocorre apenas quando existem lances dentro da faixa $5 \%$ acima do vencedor da etapa anterior, é do tipo aberto e descendente. Nessa segunda rodada, os lances são feitos publicamente, em ordem decrescente, a partir do lance vencedor da etapa anterior, até que apenas um concorrente fique na disputa, vencendo-a. O vencedor, então, firmará um contrato com o governo, acordando a receita que deverá receber e as características da concessão que deverá administrar.

Como a concessão resulta em monopólio, a análise da competição no segmento de transmissão de energia deve considerar a competição para cada lote leiloado durante o processo licitatório. Adequadamente desenhados, os leilões permitem a outorga das concessões às empresas mais eficientes e capazes de fornecer o serviço ao menor custo, entre as concorrentes. É importante que a pressão competitiva nos leilões induza as firmas a lances menores. Com isso, o governo pode planejar e estabelecer a oferta dos serviços de infraestrutura sem precisar arcar com os custos e procedimentos de gestão ligados à provisão dos serviços. Assim, o instrumento do leilão evita que a seleção das empresas ocorra em função de favoritismos do gestor público e não da eficiência econômica das empresas (OCDE 2008).

A competitividade em um leilão relaciona-se, em geral, à possibilidade de participação do maior número possível de fornecedores na licitação e à efetiva rivalidade entre eles. Nos leilões de transmissão de energia, duas ou mais empresas podem se reunir sob a forma de um consórcio e submeter um único lance. Propostas conjuntas podem reduzir o número de competidores quando as empresas envolvidas têm capacidade de apresentar propostas separadas, e também podem ser um instrumento para partilha de lucros entre concorrentes em conluio, reduzindo a rivalidade na disputa, tornando-a anticompetitiva (OCDE 2008). Os consórcios podem também permitir a entrada de participantes que não conseguiriam disputar o leilão isoladamente. Em alguns países, os

\footnotetext{
${ }^{1} \mathrm{O}$ leilão anglo-holandês é formado por uma primeira etapa ascendente (modelo inglês), em que o preço é elevado continuamente até restarem apenas dois competidores. Em seguida, esses dois entregam um último lance, não inferior ao maior lance do leilão inglês, em etapa selada (modelo holandês).
} 
consórcios só são permitidos se as empresas consorciadas não tiverem condições de competir naquele leilão de forma isolada (Albano et al. 2008). Nessa condição, os consórcios eliminam barreiras à entrada e permitem a apresentação de maior número de propostas ao contratante, tornando-se competitivos. Assim sendo, os efeitos da participação dos consórcios sobre a competição são ambíguos.

Além de modificar o número de participantes, os consórcios podem alterar as condições de acesso a informações ou recursos pelas firmas consorciadas (Iimi 2004). No Brasil, efeitos competitivos de consórcios foram encontrados em leilões de blocos de petróleo e gás, com quatro ou cinco participantes. Acima de cinco competidores, porém, os lances vencedores foram menos competitivos, possivelmente por uma reação dos participantes ao problema da maldição do vencedor (Moura et al. 2012). Empresas estatais, agindo individualmente ou em parcerias com empresas privadas nacionais, tiveram maior probabilidade de vencer leilões de transmissão no Brasil do que as concorrentes (Rocha et al. 2013). Isso poderia sugerir uma vantagem competitiva para esses consórcios, mas contraria o que Hirota (2006) e Nascimento (2012) encontraram. Esses dois autores verificaram uma relação negativa entre a participação de consórcios e os deságios nos leilões, indicando que os lances conjuntos foram menos eficientes que os individuais. Em estudos empíricos internacionais, em outros setores, o efeito de participação dos consórcios também é ambíguo. Iimi (2004) encontrou efeitos anticompetitivos, mas Estache \& Iimi (2009b) encontraram o resultado oposto.

O objetivo deste trabalho foi avaliar a competição nos leilões de transmissão de energia elétrica no Brasil, com ênfase no efeito da participação dos consórcios nos lances e deságios. Em particular, questionaram-se quais foram os efeitos dos consórcios nos leilóes de transmissão de energia elétrica, no Brasil, de 2000 a 2011, em termos de custos e competição. A hipótese básica adotada foi que a participação das firmas por meio de consórcios teve efeito não competitivo no período analisado. Assim, na média, foram esperados lances maiores e deságios menores para o consórcio em comparação aos lances e deságios para firmas que participam isoladamente.

Na próxima seção, detalham-se as características tanto do sistema de transmissão de energia elétrica no Brasil quanto do processo licitatório. Na terceira seção, discutem-se os aspectos teóricos relacionados à participação de consórcios em leilões. Na quarta seção, apresentam-se os modelos e métodos econométricos utilizados na pesquisa e informa-se sobre a fonte de dados. Os resultados são apresentados na quinta seção, e as conclusões, na sexta e última seção.

\section{Sistema de transmissão de energia elétrica e processo licitatório}

O setor de energia elétrica no Brasil é formado pelas atividades de geração, transmissão, distribuição e comercialização de energia. As instalações eletricamente interligadas responsáveis pela oferta de energia a todas as regiões do país fazem parte do Sistema Interligado Nacional (SIN), dividido nos subsistemas Sul, Sudeste-Centro-Oeste, Norte e Nordeste. As regiões do SIN diferem entre si em termos de regimes pluviais e de demandas por energia, fazendose necessário um sistema de transmissão que não apenas conecte geradores 
e distribuidores geograficamente distantes, mas possibilite transferência de energia de uma região para outra, em caso de problema de abastecimento.

Em caso de necessidade de alterações nos serviços das concessões já outorgadas, o Poder Público concede autorizações ou permissões para expansões emergenciais. Entretanto, para todos os serviços de construção, operação e manutenção de novas instalações, devem ser feitos contratos de concessão de trinta anos outorgados por licitação na modalidade de leilão, em regime de monopólio regulado (Lauer 2006). Os contratos são assinados entre a Agência Nacional de Energia Elétrica (Aneel) e vencedores das licitações.

Após perceber a necessidade de novas instalações de transmissão (linhas, torres e subestações) e realizar os primeiros estudos de viabilidade, a Aneel deve elaborar e publicar um edital de licitação, a partir das recomendações da legislação específica, definindo os aspectos técnicos das instalações a ser construídas e administradas. Em cada edital, diferentes lotes serão leiloados. Esses lotes correspondem a um conjunto de instalações de transmissão, especificadas em aspectos técnicos, como tensão, localização e extensão.

A Aneel estipula uma receita anual máxima permitida (RAP) para cada lote, com base nos custos estimados de cada empreendimento, seguindo o método do fluxo de caixa descontado. No processo de definição da RAP, a agência considera o banco de preços dos investimentos próprios da transmissão, um banco de preços dos investimentos das estatais da Eletrobrás. Mesmo que se argumente que o banco seja impreciso pelo fato de empresas estatais e privadas terem sistemas de gestão de diferentes eficácias e estruturas de custos, a construção da RAP ainda é um bom indicador para a formação de expectativas de lucros por parte dos interessados no contrato (Serrato 2008, Hernández 2010).

A maior parte dos empreendimentos leiloados no período 2000-2011 estava localizada no subsistema Sudeste/Centro-Oeste (46,62\% do total leiloado). Essa região também atraiu o maior número de proponentes por lote. A menor parcela de lotes estava no subsistema Sul (16,22\% do total). Por outro lado, a extensão média das linhas era maior no Norte, assim como a máxima Receita Anual Permitida (RAP) média, haja vista a grande extensão territorial dessa região e a necessidade de atrair investidores com empreendimentos com maiores ganhos de escala.

A Tabela 1 apresenta a distribuição por subsistema do número de lotes efetivamente leiloados, da quilometragem média das linhas, da RAP média dos contratos e do total de proponentes nos leilões. A última coluna não corresponde à soma das anteriores, em razão de 11 lotes localizados simultaneamente em dois subsistemas.

Ao todo, os leilões investigados neste trabalho atraíram de um a dez proponentes (ver Figura 1), mas a maior parte das disputas ocorreu com, no máximo, quatro. Competições com mais proponentes quase não ocorreram no Norte, região com o menor número de participantes. Elas aconteceram principalmente no Sudeste/Centro-Oeste, com vários leilões com seis e oito proponentes.

Desde que atendessem às condições de pré-qualificação (ou de inscrição, a partir de 2008) estabelecidas no edital e efetuassem o depósito de garantia de proposta, podiam participar do leilão empresas nacionais ou estrangeiras, isoladamente ou reunidas em consórcio. Desde 2004, não podem mais participar dos leilões de geração e transmissão as concessionárias, permissionárias e autorizadas de serviços públicos de distribuição de energia elétrica atuantes no 
Tabela 1: Distribuição por subsistema do número de lotes leiloados, quilometragem média das linhas, média da Receita Anual Permitida máxima e número de participantes, de 2000 a 2011

\begin{tabular}{|c|c|c|c|c|c|}
\hline Dados & Norte & Nordeste & Sudeste/CO & Sul & Total $^{*}$ \\
\hline Total de lotes licitados & 24 & 34 & 69 & 32 & 148 \\
\hline $\begin{array}{l}\text { Quilometragem média } \\
(\mathrm{km})\end{array}$ & 401,79 & 228,47 & 327,36 & 144,55 & 263,1 \\
\hline $\begin{array}{l}\text { RAP média (R } \$ / \text { mil de } \\
\text { jan/2012) }\end{array}$ & 96542,69 & 48086,94 & 64300,7 & 34770,1 & 52796,1 \\
\hline Número de participantes & 85 & 136 & 302 & 122 & 606 \\
\hline
\end{tabular}

\begin{tabular}{|c|c|c|c|c|c|}
\hline \multicolumn{6}{|l|}{30} \\
\hline 25 & & & & & \\
\hline 20 & & & & & \\
\hline 15 & & & & & \\
\hline 10 & & & & & \\
\hline 0 & 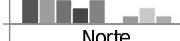 & (n) & Cirlocto & & Total* \\
\hline - 1 proponente & Norle & Nordeste & sudeste/ & sul & Tolal" \\
\hline$=2$ proponentes & 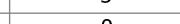 & 6 & (6) & 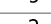 & 24 \\
\hline & 5 & 0 & 10 & 2 & 29 \\
\hline - 3 proponentes & 3 & 8 & 8 & 5 & 23 \\
\hline 4 proponentes & 2 & 3 & 7 & 6 & 17 \\
\hline - 5 proponentes & 3 & 2 & 4 & 2 & 10 \\
\hline I proponentes & 0 & 3 & 9 & 3 & 15 \\
\hline in proponentes & 1 & 2 & 1 & 1 & 5 \\
\hline = 8 proponentes & 2 & 4 & 9 & 2 & 16 \\
\hline 9 proponentes & 1 & 1 & 4 & 2 & 7 \\
\hline 10 proponentes & 0 & 0 & 2 & 0 & 2 \\
\hline
\end{tabular}

* Não corresponde à soma das colunas anteriores, em razão de 11 lotes localizados simultaneamente em dois subsistemas.

Figura 1: Relação dos lotes por número de proponentes, de 2000 a 2011, por subsistema.

Sistema Interligado Nacional (SIN) e, desde 2006, os editais preveem a possibilidade de fundos de investimento em participação também concorrerem nos leilões. Na Tabela 2 observa-se que, no período 2000-2011, os leilões atraíram 167 consórcios, 74 deles contendo pelo menos uma empresa estatal nacional, e 439 empresas individuais, das quais 83 eram estatais e 157 eram estrangeiras. Proporcionalmente, houve maior participação de isoladas estrangeiras no Sul e de isoladas estatais no Nordeste. No Sudeste/Centro-Oeste, a proporção dos consórcios com estatal e sem estrangeira foi de $49 \%$, a maior entre as regiões. No Nordeste, a situação foi outra, com $45 \%$ dos consórcios não tendo nem estatais, nem estrangeiras.

Tendo fixado a tarifa pelo preço da proposta vencedora, os contratos estabelecem a receita anual a ser obtida pela concessionária e mecanismos de reajuste e revisão tarifária, de modo a manter o equilíbrio econômico-financeiro da concessionária. Para as primeiras concessões licitadas, de 2000 a 2006, o edital previa uma receita fixa igual ao lance vencedor do leilão para os primeiros 16 anos da concessão, seguidos por uma redução de $50 \%$ na receita contratada após o $16^{\circ}$ ano. Nesses editais, reajustes e revisões de receita fica- 
Tabela 2: Tipos de proponentes nos leilões de transmissão de energia, por subsistemas, de 2000 a 2011

\begin{tabular}{lccccc}
\hline Tipos de proponentes & Norte & Nordeste & Sudeste/CO & Sul & Total $^{*}$ \\
\hline Consórcio & 28 & 31 & 87 & 36 & 167 \\
Com estatal e sem estrangeira & 10 & 6 & 43 & 12 & 67 \\
Com estrangeira e sem estatal & 6 & 11 & 11 & 7 & 31 \\
Com estatal e estrangeira & 0 & 0 & 5 & 3 & 7 \\
Sem estrangeira e sem estatal & 12 & 14 & 28 & 14 & 62 \\
Individual & 57 & 105 & 215 & 86 & 439 \\
Estatal nacional & 10 & 26 & 35 & 17 & 83 \\
Estrangeira & 22 & 28 & 81 & 37 & 157 \\
Nacional não estatal & 25 & 51 & 99 & 32 & 199 \\
Estrangeira & 28 & 39 & 97 & 47 & 195 \\
Estatal & 20 & 32 & 83 & 32 & 157
\end{tabular}

${ }^{*}$ Não corresponde à soma das colunas anteriores, em razão de 11 lotes localizados simultaneamente em dois subsistemas.

Fonte: Resultados da pesquisa.

vam acordadas em contrato, sem previsão de revisão tarifária periódica. Os editais de 2007 em diante, por outro lado, eliminaram essa redução de 50\% no valor da receita mantendo, por todo o período, o valor da proposta financeira vencedora do leilão como a receita anual da concessão. Esses editais também previram revisões periódicas a cada cinco anos, no valor da receita anual, nos termos dos contratos e em conformidade com parâmetros regulatórios estabelecidos pela ANEEL.

Uma medida que capta o quão menor foi o lance em relação à receita máxima permitida (RAP) é o deságio, diferença entre a RAP e o lance dado, dividido pelo valor da RAP. Na média, os lotes localizados no Nordeste foram os que tiveram maior deságio (ver Tabela 3).

Tabela 3: Deságios médios dos lances vencedores por subsistema, de 2000 a 2011

\begin{tabular}{lccccc}
\hline & Norte & Nordeste & Sudeste/CO & Sul & Total $^{*}$ \\
\hline $\begin{array}{l}\text { Deságio médio dos lances } \\
\text { vencedores }\end{array}$ & $23,43 \%$ & $34,82 \%$ & $26,66 \%$ & $22,99 \%$ & $27,17 \%$ \\
Número de lotes leiloados & 24 & 34 & 69 & 32 & 148 \\
\hline
\end{tabular}

${ }^{*}$ Não corresponde à soma das colunas anteriores, em razão de 11 lotes localizados simultaneamente em dois subsistemas.

Fonte: Resultados da pesquisa.

Os deságios foram baixos nos primeiros leilões realizados, tanto em relação às médias dos vencedores por edital (ver Figura 2) como em relação a todos os lances (ver Figura 3), com valores maiores a partir de 2003. O país ainda enfrentava problemas de financiamento no setor e a crise de racionamento em 2001, deixando os investidores privados mais cautelosos (Serrato 2008). Posteriormente, houve ingresso de firmas estrangeiras nos leilões e as firmas estatais integrantes do Plano Nacional de Desestatização puderam participar dos leilões, o que contribuiu para o aumento dos deságios. Além de as incertezas políticas da transição para o governo Lula terem sido reduzidas, o marco regulatório do setor elétrico continuou sendo aperfeiçoado, com destaque para as reformas de 2004. Por outro lado, o risco de novos racionamentos voltou a causar preocupação em 2007. Em 2008, houve a crise financeira inter- 
nacional. Tais fatores podem ter contribuído para menores deságios em 2008. Nos anos seguintes, eles tiveram aumentos gradativos e, então, voltaram a se reduzir, porém, mantendo-se em níveis superiores aos observados no início da implantação do programa de leilões, um resultado a princípio bem-sucedido para a proposta da agência reguladora de estimular a competição.

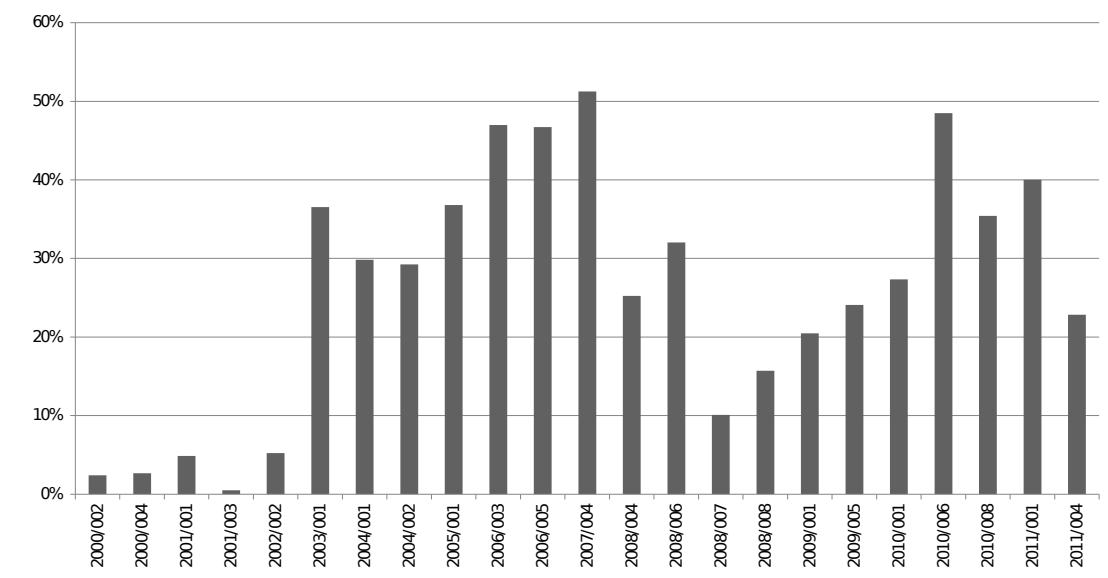

Figura 2: Evolução dos deságios médios dos lances vencedores (eixo vertical) nos editais de licitação para linhas de transmissão de energia elétrica de 2000 a 2011 (eixo horizontal).

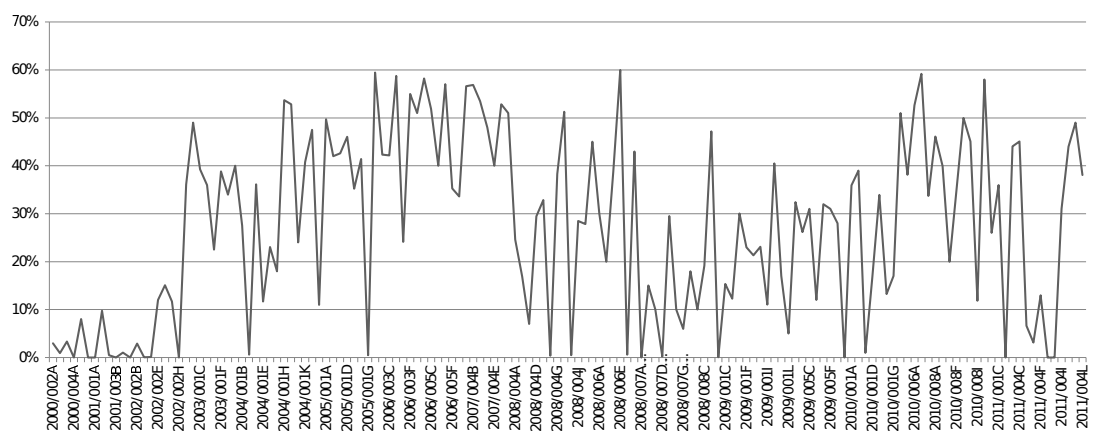

Fonte: Resultados da pesquisa.

Figura 3: Evolução dos deságios dos lances vencedores (eixo vertical) nos leilões de linhas de transmissão de energia elétrica de 2000 a 2011 (eixo horizontal).

\section{Aspectos teóricos relacionados à participação de consórcios em leilões}

Diversas são as razões que podem levar à formação dos consórcios: extrair vantagens de particularidades específicas de cada região, explorar possíveis sinergias entre linhas de transmissão e, entre outras, conseguir vantagens derivadas de suas estruturas de capital (público ou privado) ou de qualquer outra 
característica das empresas, como, por exemplo, a nacionalidade, o ramo de atividade e o grupo econômico a que pertencem. Com tantas possibilidades, o impacto dos consórcios sobre a competição pode variar.

Iimi (2004) destacou cinco possíveis causas para a formação dos consórcios. Em primeiro lugar, tem-se a perspectiva de restrição de recursos, sejam eles técnicos, humanos ou financeiros. Nessa abordagem, a formação dos consórcios reduz barreiras à entrada, permitindo o acesso de algumas firmas à competição e, portanto, tornando-a mais intensa. Isso é particularmente importante quando o projeto está associado a consideráveis riscos políticos e incertezas sociais ou requer tecnologias avançadas ou grande quantidade de capital. Assim, com a viabilidade de formação dos consórcios, é possível dividir custos e compartilhar recursos, de modo a aumentar a eficiência das firmas e criar condições de participação no certame.

No caso dos leilões de transmissão de energia, existe uma Receita Anual Permitida máxima, que funciona como teto para os lances. Apenas os licitantes capazes de oferecer o serviço por receita igual ou inferior ao teto (receita de reserva) poderão participar do leilão. De forma similar, se existir um custo de participação, como de preparação de lance, de assinatura de contrato ou de entrada na disputa, então, nem todas as empresas participarão do leilão, pois nem todas desejam ou podem arcar com esses custos. Nesses casos, consórcios poderiam ser formados para garantir a possibilidade de as empresas entregarem lances abaixo do teto ou para arcar com alguns custos de participação, como a exigência de depósitos de garantia de proposta. Nesse segmento, como os maiores custos do projeto são de construção, a participação de consórcios com empresas construtoras e de engenharia também pode garantir vantagens por compartilhamento de recursos técnicos.

A segunda causa para a formação dos consórcios é o compartilhamento de informações e expectativas privadas, melhorando a estimativa do valor do objeto leiloado (Iimi 2004). Quando a estimativa desse valor é imprecisa, as empresas podem ficar excessivamente cautelosas em relação aos lances dados, com receio de vencer por ter sido otimistas, sobrevalorizando o bem. Se a formação dos consórcios melhora a qualidade das estimativas, o número de participantes poderá ser menor, mas cada concorrente consorciado poderá submeter lances mais agressivos. Incertezas geológicas podem gerar assimetria de informação em leilões de petróleo e gás, por exemplo, induzindo à formação de consórcios com vistas a reduzir riscos associados à atividade (Moura et al. 2012).

Nos leilões de transmissão de energia, cada licitante faz suas próprias pesquisas, estimando valores possivelmente diferentes dos de seus concorrentes. Porém, como as expectativas de investimento e receita têm balizadores de mercado (como a RAP máxima), os lances devem tender a um único valor. Além disso, como o formato híbrido dos leilões diminui problemas de informação, não se espera que os consórcios sejam formados para compartilhar informações sobre o valor do objeto, diferentemente do caso do petróleo.

A terceira causa é a coalizão não colusiva. A restrição de recursos é tão grande que os participantes naturalmente se dividem em grandes grupos que competirão entre si. Esses consórcios, então, seriam competitivos. A quarta causa é a restrição na possibilidade de colusão em razão de fortes entrantes potenciais, de grandes firmas disputando isoladamente e de um sistema de compatibilidade de incentivos responsável pela competitividade dos lances. Nesse caso, o consórcio teria pouco efeito sobre o número de participantes ou 
sobre os lances e, em última instância, não afetaria o leilão.

Por fim, Iimi (2004) mencionou a possibilidade de colusão com intenção explícita de restringir preços e dividir o objeto entre os vencedores. Como é mais fácil coordenar decisões e fiscalizar o cumprimento de acordos quando o número de empresas no mercado é menor, os consórcios poderiam facilitar colusões por essa via.

\section{Metodologia}

\subsection{Modelos econométricos}

Na literatura empírica de leilões, a estimação dos determinantes de lances ou deságios parte, inicialmente, de estimativas utilizando o método de Mínimos Quadrados Ordinários (MQO) (Iimi 2004, De Silva et al. 2005, De Silva 2005, Rezende 2008, Estache \& Iimi 2009a,b, Carlos 2010, Estache \& Iimi 2010). Os resultados obtidos com o MQO são, então, comparados e complementados com procedimentos adicionais para explorar especificidades dos objetos de estudo ou corrigir eventuais fontes de viés da estimação por MQO.

No caso da formação dos consórcios, a decisão de formação de lances conjuntos pode afetar endogenamente a função de lances e deságios, gerando parâmetros inconsistentes em uma estimação por MQO. No leilão de transmissão de energia, as firmas escolhem participar ou não de um leilão e a forma dessa participação, ou seja, se vão participar de forma isolada ou unida a outra(s) em um consórcio. Certos fatores podem influenciar essa decisão, favorecendo uma escolha em detrimento da outra. É provável que firmas menos eficientes e com altos custos operacionais procurem formar consórcios com mais frequência, em uma perspectiva de restrição de recursos.

Não é possível observar todos os fatores que afetam essa decisão. Alguns são características do leilão e do objeto leiloado, outros são atributos privados, como as preferências das firmas. Assim, o tipo de participante (consórcio ou individual) provavelmente não é determinado independentemente de outros fatores que afetam os lances e os deságios, havendo uma correlação entre eles. Nesse caso, a perspectiva de vitória e lucro, incorporada à função de lances e deságios, afeta a decisão da firma de optar por uma formação e não por outra. A expectativa de ganho com um lance conjunto deve ser ponderada em relação à expectativa com um lance isolado, pois, entre consorciadas, lucros são compartilhados e devem a princípio superar os lucros que cada uma conseguiria obter se disputasse individualmente, caso isso fosse possível. Além disso, o valor esperado de lance capaz de vencer o leilão, somado às necessidades do projeto e outros aspectos das firmas, podem indicar a elas quais formações de consórcio priorizar e com quais firmas buscar associação.

Como algumas empresas têm maior probabilidade de formar consórcios, a separação dos participantes entre consórcios e firmas isoladas não é aleatória, causando viés de seletividade. Para corrigir esse viés de seletividade, foi adotada a metodologia empregada por Estache \& Iimi (2009b), com variáveis similares àquelas utilizadas em estudos internacionais. A endogeneidade da decisão de participação isolada ou em consórcio foi detectada por meio do teste de Durbin, Wu, Hausman ${ }^{2}$. Em seguida, um modelo de efeito de tratamento, em dois estágios, foi estimado. Esse modelo estima o efeito de

\footnotetext{
${ }^{2}$ Ver, por exemplo, Cameron \& Trivedi (2009).
} 
um tratamento binário (no caso, ser ou não consórcio) em uma variável contínua (dependente), condicionado em algumas variáveis independentes (que incluem instrumentos). Destaca-se, porém, que não é possível medir o efeito líquido do tratamento, pois não é possível observar a participação de uma empresa, em um mesmo leilão, como consórcio e como participante isolada. Ao observar o tipo de participante no leilão, ou ele é um consórcio ou é uma firma individual, e a separação entre os tipos não é aleatória, como já discutido.

O modelo básico, estimado inicialmente por Mínimos Quadrados Ordinários (MQO), assumiu a seguinte especificação:

$$
Y_{i t}=\alpha_{0}+\alpha_{1} N_{1}+\alpha_{2} D C_{i t}+\alpha_{3} E X T_{t}+\alpha_{4} R A P_{t}+\alpha_{5} D S U B_{i t}+\varepsilon_{i t},
$$

a partir do qual foram estimados quatro modelos. Nos estudos de leilões de transmissão, observa-se o emprego das duas variáveis dependentes: deságio (Hirota 2006, Nascimento 2012, Rocha et al. 2013) e lance ou logaritmo do lance (Carlos 2010). Em cada modelo, neste trabalho, uma variável dependente diferente foi considerada: logaritmo do lance do participante $i$, no leilão $t$ (lance $_{i t}$ ) logaritmo do lance do participante vencedor no leilão $t$ (lvencedor ${ }_{t}$ ), deságio do lance do participante $i$ no leilão $t\left(\right.$ desagio $_{i t}$ ) e deságio do lance vencedor no leião $t$ (dvencedor ${ }_{t}$ ). Por meio delas, foi possível estudar a influência dos consórcios nos custos (lances) e na competição (deságios) dos leilões.

Os modelos que consideram apenas as observações relativas aos lances vencedores apresentam um viés de seletividade em razão da classificação dos vencedores (Rocha et al. 2013). Neste estudo, como em (Carlos 2010) e (Nascimento 2012), esse viés foi desconsiderado. Ao ignorar esse viés, a interpretação dos resultados pode gerar conclusões falsas, segundo Rocha et al. (2013). Entretanto, neste trabalho, a interpretação desses modelos foi complementada com aquela extraída dos modelos que incluem todas as observações, tanto dos lances vencedores quanto dos perdedores, e os resultados foram similares. Assim, considerando a similaridade das conclusões e o foco de correção do viés de seleção na decisão de formação de consórcios, ignorar o viés de seleção dos vencedores não se mostrou um problema significativo.

O lance dado pelo participante $i$, no leilão $t$, representou a Receita Anual, em R\$ de janeiro de 2012, que o participante desejava receber em troca da prestação do serviço leiloado. Foi considerada a proposta entregue na primeira fase, ou o último lance em caso de repique a viva voz. Os lances estão bastante relacionados aos investimentos necessários para as instalações e podem oferecer indícios sobre a relação entre a participação dos consórcios e o tamanho dos projetos. Os deságios, por sua vez, sinalizam níveis de agressividade dos lances, sendo a diferença entre a receita máxima (teto do leilão, chamada receita de reserva) e o lance dado, dividido pelo valor da receita de reserva. Quanto maior a competição, maiores os deságios esperados, pois, para vencer a disputa, as firmas devem oferecer lances com maior diferencial em relação à receita máxima.

Os estudos de leilões sugerem que lances e deságios podem ser determinados por características dos objetos leiloados, pelo formato da disputa, pelas características do leilão (como valor máximo permitido e processos de qualificação), pelas características do próprio licitante e também pelos aspectos do ambiente institucional (como reputação do vendedor e risco regulatório). Algumas variáveis explicativas utilizadas neste trabalho estavam relacionadas 
aos leilões ou aos objetos leiloados, assumindo um valor para cada leilão $t$, independentemente do participante $i$, como o número de competidores $\left(N_{t}\right)$, a extensão das linhas leiloadas $\left(E X T_{t}\right)$ e o logaritmo da receita máxima permitida no edital $\left(R A P_{t}\right)$, que representou a receita de reserva do leilão. Também foi empregada uma variável para captar potencial sinergia das linhas, $D S U B_{i t}$, similar à de Rocha et al. (2013), com valor um para o caso em que a empresa tivesse sede no mesmo subsistema da linha ou subestação de transmissão leiloada no leilão $t$. Por fim, a variável principal deste estudo, $D C_{i t}$, com valor um quando o licitante $i$ no leilão $t$ era um consórcio e zero quando era uma empresa disputando individualmente. O termo de erro $\varepsilon_{i t}$ inclui, como já é usual, outros aspectos que afetam a variável dependente.

O número de competidores no leilão $t\left(N_{t}\right)$ foi o número de lances dados na primeira fase do leilão. Ou seja, o número de consórcios e firmas individuais que estavam aptos a participar dos leilões e efetivamente entregaram uma proposta de receita no momento da disputa. Espera-se uma relação negativa entre o número de competidores $\left(N_{t}\right)$ e o lance dado e uma relação positiva com o deságio.

Para controlar as características dos objetos leiloados, foi utilizada a extensão $\left(E X T_{t}\right)$ quilométrica das linhas de transmissão, associada a necessidades maiores ou menores de capacidades de administração e construção, por parte das empresas e consórcios concorrentes. Quando o lote incluía apenas subestações de transmissão, foi considerada uma extensão quilométrica igual a um. Linhas de transmissão maiores devem estar relacionadas a ganhos de escala, percebidos, por exemplo, nas compras maiores de materiais e equipamentos. Esperava-se, então, que seu impacto sobre os lances fosse positivo (negativo para o deságio), como em Carlos (2010).

A Receita Anual Permitida $\left(R A P_{t}\right)$ máxima, por outro lado, estava não apenas associada ao objeto leiloado, mas também a uma característica do leilão. Por configurar uma receita de reserva, ela, naturalmente, limitou os lances dados a valores iguais ou inferiores a ela. Além disso, dado um componente comum de valores, a teoria sugere que os lances convergem para o valor da receita teto. Assim, receitas maiores estariam associadas a lances maiores. Por outro lado, resultados de receita ou investimento não tiveram impactos sobre deságios em leilões de transmissão (Nascimento 2012).

Esperava-se que a existência de sinergia estivesse associada a lances menores e deságios maiores, tal como sugerido por Hirota (2006). Rocha et al. (2013), com variável semelhante à deste trabalho, identificaram que a probabilidade de vencer leilões estava relacionada à presença de sinergias de localização. O uso de uma variável que captasse melhor a sinergia deveria ser buscado. DSUB deveria ser negativa se houvesse sinergia, pois, nesse caso, existiriam ganhos econômicos e os custos seriam menores. Quanto à variável de consórcios, embora seu efeito seja ambíguo, esperava-se um resultado anticompetitivo, como encontrado em Hirota (2006) e Nascimento (2012).

Em resumo, as variáveis dependentes e explicativas utilizadas na estimação por Mínimos Quadrados Ordinários podem ser vistas na Tabela 4.

Detectado o problema de endogeneidade, estimou-se uma variável $\widehat{D C}_{i t}$, que foi utilizada no segundo estágio do modelo de efeito de tratamento como instrumento da variável endógena binária (equação 2).

$$
Y_{i t}=\alpha_{0}+\alpha_{1} N_{t}+\alpha_{2} \widehat{D C}_{i t}+\alpha_{3} E X T_{t}+\alpha_{4} R A P_{t}+\alpha_{5} D S U B_{i t}+\varepsilon_{i t}
$$


Tabela 4: Descrição das variáveis utilizadas na estimação econométrica

\begin{tabular}{|c|c|c|}
\hline Tipo & Variáveis & Descrição das variáveis \\
\hline Dependentes & $\begin{array}{c}\text { lance }_{\text {it }} \\
\text { lvencedor }_{t} \\
\text { desagio }_{i t} \\
\text { dvencedor }_{t}\end{array}$ & $\begin{array}{l}\text { Logaritmo do lance }(\mathrm{R} \$) \text { do participante } i \text { no leilão } t \\
\text { Logaritmo do lance }(\mathrm{R} \$) \text { do vencedor no leilão } t \\
\text { Deságio do lance } i \text {, no leilão } t \text {, em relação à receita máxima } \\
\text { permitida no edital } \\
\text { Deságio do lance vencedor, no leilão } t \text {, em relação à receita } \\
\text { máxima permitida no edital }\end{array}$ \\
\hline Explicativas & $\begin{array}{l}D C_{i t} \\
N_{t} \\
E X T_{t} \\
R A P_{t}\end{array}$ & $\begin{array}{l}\text { Variável binária que representa se o competidor } i \text { é um } \\
\text { consórcio }(D C=1) \text {, no leilão } t \\
\text { Número de competidores efetivos, ou seja, que entregaram } \\
\text { lances, o leilão } t \\
\text { Extensão quilométrica da(s) linha(s) leiloada(s) no leilão } t \\
\text { Logaritmo da receita máxima (R\$) permitida no edital, no leilão } \\
t \\
\text { Variável binária com valor um quando o participante } i \text { opera } \\
\text { alguma concessão de transmissão no mesmo subsistema em que } \\
\text { se localiza o objeto leiloado no leilão } t\end{array}$ \\
\hline
\end{tabular}

Fonte: Elaboração própria

em que as variáveis são as mesmas já mencionadas anteriormente na equação (1), exceto pela variável consórcios, obtida no primeiro estágio da estimação. No primeiro estágio da estimação foi feita uma regressão introduzindo a variável latente não observada $D C_{i t}^{*}$, que determinava se $D C=1$ ou $D C=0$. Com isso, foi possível verificar quais características mais afetaram a probabilidade de a firma participar ou não nos leilões sob a forma conjunta, o que foi feito a partir da estimação de um modelo Probit. O modelo de seleção (equação 3) pode ser escrito como a seguir:

$$
D C_{i t}=\left\{\begin{array}{l}
1, \text { se } D C_{i t}^{*}=X_{i t}^{\prime} \gamma+Z_{i t}^{\prime} \delta+v_{i t} \geq 0 \\
0, \text { caso contrário }
\end{array}\right.
$$

em que $X$ representou as variáveis exógenas da equação (1) e $Z$ representou as variáveis instrumentais, também chamadas de instrumentos excluídos, ou simplesmente instrumentos, que não faziam parte da equação (1). Uma variável instrumental $Z$ deve satisfazer duas condições básicas: não ser correlacionada com o erro da equação (1) e ser correlacionada com a variável endógena $D C$.

Os instrumentos deste trabalho foram escolhidos a partir do que foi feito em Estache \& Iimi (2009b). Eles utilizaram dois tipos de variáveis: de restrição de capacidade e de governança. ${ }^{3}$ Utilizaram como instrumento, por exemplo, o total de contratos (em dólares) assinados pelos participantes três anos antes do leilão. Medida similar foi empregada na análise dos determinantes dos lances por De Silva et al. (2005). Se os consórcios são formados por motivos de restrição de capacidade, firmas administrando muitas concessões deveriam se unir em consórcios. Dessa forma, os consórcios deveriam estar associados

\footnotetext{
${ }^{3}$ Nas variáveis de governança, Estache \& Iimi (2009b) utilizaram indicadores como estabilidade política, qualidade regulatória, controle de corrupção, além de outras que captavam efeitos institucionais. As medidas mais próximas nesse sentido, para o caso brasileiro de transmissão de energia, são os indicadores anuais de governança produzidos pelo Banco Mundial (The Worldwide Governance Indicators - WGI), o risco país e o índice do setor elétrico (IEE) na Bolsa de Valores. Porém, nenhum desses indicadores tem boa variabilidade para ser incluído no estudo e tampouco abordam majoritariamente questões do segmento de transmissão.
} 
a maior número de contratos do que participantes individuais. Assim, considerando a limitação dos dados, construiu-se a variável CONTRATO, com o número total de contratos assinados pela empresa (ou a média, para consórcios) na data da disputa do leilão. Essa medida desconsiderou diferenças em valores e dificuldades de execução dos diferentes contratos assinados, mas foi a melhor aproximação disponível à variável usada em Estache \& Iimi (2009b).

Estache \& Iimi (2009b) destacaram a importância da participação de empresas estrangeiras em leilões de infraestrutura. A parceria entre estrangeiras e nacionais envolveria o compartilhamento de recursos financeiros e técnicos das primeiras e os conhecimentos de aspectos locais, como acesso à mão de obra e aos detalhes de regulação, das últimas. No caso brasileiro de transmissão de energia, a entrada de empresas estrangeiras, como o caso das empresas espanholas, é frequentemente associada aos elevados deságios nos leilões. Cezario (2007) discutiu a crescente participação das empresas estrangeiras no setor e sua competição mais agressiva. Segundo a autora, estrangeiras têm incentivos em seus países de origem, além de contarem com financiamentos baratos do BNDES, no Brasil, o que as permitiria algumas vantagens competitivas. Assim, foi utilizada a variável DESTR, que assumiu valor unitário para empresas estrangeiras (ou consórcios com pelo menos uma estrangeira) e zero, caso contrário.

Outra variável relevante é o ramo de atividade da empresa. Na perspectiva de compartilhamento de recursos, pode ser interessante formar consórcios com empresas construtoras e que oferecem serviços de engenharia. Tais firmas arcariam com os custos e riscos das atividades iniciais da concessão, predominantemente de construção. A variável DEPC teve, então, valor 1 para a empresa ou consórcio com pelo menos uma empresa que tivesse como atividade principal ou secundária a construção ou a prestação de serviços de engenharia, assumindo o valor zero nos demais casos. As vantagens relativas a esse tipo de empresa já foram sugeridas nos estudos de Hirota (2006), Carlos (2010) e de Rocha et al. (2013), como possíveis determinantes de lances e deságios. Neste trabalho, investigou-se o impacto dessas variáveis nos lances e deságios via impacto na decisão de formação de consórcios. Portanto, as variáveis instrumentais utilizadas neste trabalho foram CONTRATO, DESTR e DEPC, referentes ao número de contratos assinados e à presença de firmas estrangeiras e de construção, respectivamente.

É importante destacar que, embora tenham sido coletados lances de diversas empresas e consórcios em leilões realizados ao longo do tempo, os dados deste trabalho não caracterizaram um painel típico quando todas as observações eram analisadas. Em cada período (leilão), um grupo de empresas e consórcios participava dos leilões, sendo provável que cada conjunto fosse diferente do anterior. Como os lances em cada leilão poderiam ser realizados por empresas distintas ao longo do tempo (como de fato ocorreu), não sendo possível acompanhar os lances de um proponente (unidade) ao longo dos leilões, utilizar dados empilhados (modelo pooled) era mais apropriado. Quando apenas os vencedores foram analisados, os dados se estruturaram como uma série temporal, em que cada lote foi leiloado em um tempo $t$. Neste trabalho, todos os procedimentos foram realizados utilizando-se o programa econométrico Stata11. 


\subsection{Fonte de dados}

O processo de coleta de dados foi feito por meio do cruzamento de informações que estavam disponibilizadas principalmente em sites do governo, como a página da Aneel e da Receita Federal, site da BM\&FBOVESPA, além de dados disponibilizados em outros estudos, como o de Cezario (2007). Esses sites foram acessados de junho de 2011 a maio de 2012, permitindo a criação de uma base de dados sobre os leilões de transmissão de energia realizados no Brasil, de 2000 a setembro de 2011, período anterior a uma alteração nas regras dos leilões. Os lances, assim como a Receita Anual Permitida, tiveram seus valores monetários atualizados para o dia primeiro de janeiro de 2012, por meio do índice IGPM da FGV.

Para definir a entrada ou saída de uma empresa do contrato de concessão, foi considerada a data de publicação da resolução autorizativa pela Aneel. Em relação às empresas, aquelas que apenas tiveram a razão social alterada foram consideradas como uma só. De maneira similar, participações de firmas que eventualmente haviam sofrido cisão em razão de impedimentos legais de participação simultânea nos segmentos de distribuição e transmissão, caso de algumas estatais, foram consideradas como se fossem a mesma empresa. Analogamente, cada consórcio foi considerado um único participante, independentemente de quantas empresas o formavam, e, dada uma formação, independentemente de sua nomenclatura.

Neste trabalho, foram considerados os editais de licitação para outorga de concessão do serviço público de transmissão de energia elétrica no Brasil, licitados entre 2000 e 2011. O primeiro edital de 2000 e o último de 2011 foram excluídos da análise por seguirem regras um pouco diferentes em relação aos demais.

Quatro lotes foram licitados, mas não apresentaram proponentes ou foram cancelados, sendo relançados em editais posteriores (C do edital 003/2001, D do 006/2008 e D e E do 008/2010). O mesmo ocorreu com o edital 001/2006, que foi inteiramente suspenso e depois relançado. Outro fato relevante a ser destacado refere-se à desclassificação da opção tecnológica HB no edital 007/2008, suspendendo todos os leilões dessa modalidade.

Foram efetivamente realizados 148 leilões (com vencedores), ocorridos no total de 23 datas entre 2000 e 2011. Em dois dos 148 lotes estudados, a empresa vencedora não assinou o contrato com a Aneel: lote $C$ do edital 001/2001, em que venceu a PEM Engenharia, e lote B do edital 001/2009, arrematado pela CME - Construção e Manutenção Eletromecânica. No primeiro caso, a obra foi considerada prioritária, e uma autorização foi concedida à concessionária Furnas para administração do contrato (ANEEL 2012).

\section{Resultados e discussão}

\subsection{Resultados dos testes iniciais para especificação dos modelos}

Para detectar possíveis problemas de estimação na análise dos leilões de transmissão de energia realizados entre 2000 e 2011, foram feitos testes de multicolinearidade, heterocedasticidade e autocorrelação. Em nenhum modelo houve indícios fortes de elevada correlação entre as variáveis independentes (multicolinearidade). Os erros das regressões estimadas foram homocedásticos, a 5\% de significância, no modelo com os lances vencedores como variável 
dependente, e a 10\% de significância, nos modelos com todos os lances e deságios. A correlação serial, por sua vez, foi detectada nas duas especificações de variáveis dependentes, no grupo dos vencedores, a 1\% de significância.

Para avaliar a presença da endogeneidade na variável binária de consórcios (DC), foram realizados o teste de Durbin-Wu-Hausman, no caso dos Mínimos Quadrados Ordinários, e o teste da correlação, no caso do método de efeito de tratamento. Pelos dois testes (ver Tabela 6), rejeitou-se a hipótese de que a variável fosse exógena em qualquer especificação de variável dependente, como esperado neste trabalho. Diante disso, estimou-se o modelo de efeito de tratamento, ${ }^{4}$ que utiliza variáveis instrumentais.

Ao utilizar variáveis instrumentais, são necessários alguns cuidados. Os instrumentos precisam ser válidos (não correlacionados com o erro), relevantes (correlacionados com a variável explicativa endógena), fortes (altamente correlacionados com a explicativa endógena) e, sobretudo, precisam ser definidos a partir de boa fundamentação teórica.

Só é possível testar a validade dos instrumentos quando o modelo é sobreidentificado (apresenta mais instrumentos do que variáveis). Para testar a validade e a força dessas variáveis (Tabela 6) foram feitos testes a partir das estimativas obtidas de um modelo, com as mesmas variáveis, estimado por MQ2E. O teste de sobreidentificação utilizado neste trabalho, que permite verificar a adequação dos instrumentos na estimativa, não rejeitou a validade dos instrumentos.

A rejeição da hipótese de validade dos instrumentos implica a necessidade de reavaliação dos instrumentos ou reflexão sobre as vantagens de se instrumentar as variáveis em detrimento do MQO. Um bom resultado, porém, não é condição necessária nem suficiente para a validade dos instrumentos e não necessariamente melhora as estimativas. Como estimativas com variáveis instrumentais podem ser imprecisas, um bom resultado pode ser gerado mesmo na ausência de validade. Um resultado ruim no teste, por outro lado, também pode ser evidência de heterogeneidade no efeito de tratamento e não de falha na identificação. Por isso, o resultado não é decisivo e a escolha dos instrumentos deve estar bem fundamentada nas relações causais esperadas (Angrist \& Pischke 2008). No caso, os instrumentos são exógenos e precedem a decisão de formação dos consórcios em aspectos identificados em modelos teóricos.

Por termos apenas um regressor endógeno, foi possível avaliar a fraqueza dos instrumentos por meio do $R^{2}$ e da estatística F parcial. Pela regra prática, os instrumentos foram fracos nos modelos com lances vencedores, reduzindo a eficiência dos estimadores desses modelos. Embora os instrumentos tenham sido correlacionados com a variável endógena, essa correlação não foi elevada. Assim, os resultados desses modelos devem ser interpretados com cautela. Nas estimativas com todos os lances dados, por outro lado, os instrumentos escolhidos foram fortes e válidos.

Ressalta-se que outros instrumentos foram testados, como variáveis para captar o risco-país (efeito institucional), o número de vitórias (eficiência de alguns participantes na disputa) e o número de participações anteriores em leilões (ganhos de conhecimento nesse tipo de competição). A combinação utilizada foi a que mostrou os melhores resultados em termos de validade e

\footnotetext{
${ }^{4}$ Além do efeito de tratamento, foram feitas outras estimações utilizando-se variáveis instrumentais: pelo Método dos Momentos Generalizados (GMM), por Mínimos Quadrados em dois Estágios (MQ2E) e por Máxima Verossimilhança de Informação Limitada (LIML). Os resultados, entretanto, foram similares.
} 
Tabela 5: Testes de multicolinearidade, heterocedasticidade e autocorrelação, para os modelos estimados, de 2000 a 2011

\begin{tabular}{lcccccc}
\hline \multirow{2}{*}{$\begin{array}{l}\text { Variável Dependente } \\
\text { do Modelo }\end{array}$} & \multicolumn{2}{c}{ Multicolinearidade ${ }^{(*)}$} & \multicolumn{2}{c}{ Heterocedasticidade $^{(* *)}$} & \multicolumn{2}{c}{ Autocorrelação $^{(* * *)}$} \\
\cline { 2 - 6 } & FIV & Número Condicional & Breusch-Pagan & Prob> $\lambda^{2}$ & Breusch-Godfrey $^{\text {Prob }>\lambda^{2}}$ \\
\hline Ln do Lance do vendedor & 1,47 & 57,5 & 5,000 & 0,025 & 9,068 \\
Deságio do vencedor & & & 1,12 & 0,291 & 13,436 \\
Ln do Lance do participante & 1,43 & 60 & 1,05 & 0,3057 & - \\
Deságio do participante & & & 2,39 & 0,1223 & - \\
\hline$*$
\end{tabular}

\footnotetext{
${ }^{*}$ Como regra prática, considera-se um problema sério quando FIV $>10$.
}

** Hipótese nula: variância constante (erros homocedásticos).

*** Hipótese nula: não há correlação serial.

Fonte: Resultados da pesquisa. 
Tabela 6: Testes de endogeneidade e de validade e força dos instrumentos, para os modelos com todos os dados e apenas com os dados dos vencedores, de 2000 a 2011

\begin{tabular}{|c|c|c|c|c|c|c|c|c|c|c|}
\hline \multirow{3}{*}{$\begin{array}{l}\text { Especificação } \\
\text { Variável } \\
\text { Dependente }\end{array}$} & \multicolumn{6}{|c|}{ Endogeneidade } & \multicolumn{2}{|c|}{ Validade $^{(* * *)}$} & \multicolumn{2}{|c|}{$\operatorname{Força~}^{(* * * *)}$} \\
\hline & \multicolumn{4}{|c|}{ Durbin Wu Hausman ${ }^{(*)}$} & \multicolumn{2}{|c|}{$\rho(\mathrm{MTE})^{(* *)}$} & \multirow{2}{*}{$\lambda^{2}$} & \multirow{2}{*}{$p>\lambda^{2}$} & \multirow{2}{*}{$\begin{array}{c}R^{2} \\
\text { parcial }\end{array}$} & \multirow{2}{*}{$\mathrm{F}$} \\
\hline & $\lambda^{2}$ & $p>\lambda^{2}$ & $F$ & $p>\mathrm{F}$ & $\lambda^{2}$ & $p>\lambda^{2}$ & & & & \\
\hline Ln do lance vencedor & 2,953 & 0,086 & 3,199 & 0,076 & $-0,614$ & 0,026 & 0,138 & 0,933 & 0,160 & 8,183 \\
\hline $\begin{array}{l}\text { Deságio do lance } \\
\text { vencedor }\end{array}$ & 2,810 & 0,094 & 3,033 & 0,084 & 0,540 & 0,063 & 0,515 & 0,773 & 0,160 & 8,183 \\
\hline $\begin{array}{l}\text { Ln do lance do } \\
\text { participante }\end{array}$ & 4,464 & 0,035 & 4,445 & 0,035 & 11,810 & 0,001 & 0,939 & 0,625 & 0,214 & 56,987 \\
\hline $\begin{array}{l}\text { Deságio do lance do } \\
\text { participante }\end{array}$ & 6,369 & 0,012 & 6,362 & 0,012 & 12,440 & 0,000 & 0,987 & 0,611 & 0,214 & 56,987 \\
\hline
\end{tabular}

* Hipótese nula: as variáveis são exógenas.

** Hipótese nula: $\rho=0$ (variáveis são exógenas).

*** Hipótese nula: os instrumentos são válidos.

**** Como regra prática, $\mathrm{F}<10$ e $R^{2}$ parcial baixo indicam instrumentos fracos.

Fonte: Resultados da pesquisa. 
força, estando as variáveis número de contratos, presença de empresa estrangeira e presença de construtora relacionadas a outras variáveis empregadas na literatura como possíveis explicações para a formação de consórcios.

\subsection{Resultados das estimativas sobre lances e deságios nos leilões de transmissão de energia elétrica, de 2000 a 2011}

Inicialmente, serão apresentados os resultados da estimação dos modelos com as propostas vencedoras apenas (Tabela 7). Os modelos A e B tiveram como variável dependente o logaritmo natural dos lances vencedores. Os modelos $\mathrm{C}$ e D, por sua vez, tiveram os deságios dos lances vencedores. Foram apresentados os resultados por meio dos Mínimos Quadrados Ordinários (A e C), corrigindo pelo procedimento de Newey-West, para heterocedasticidade e autocorrelação. Os modelos $\mathrm{B}$ e $\mathrm{D}$, por sua vez, correspondem às estimativas utilizando o modelo de efeito de tratamento.

Um dos principais resultados encontrados, objetivo de investigação deste trabalho, foi o efeito positivo dos consórcios sobre os lances vencedores e o efeito negativo sobre os deságios desses lances. Isso significou que, na média, os consórcios venceram leilões com lances maiores e deságios menores do que os observados quando os vencedores eram participantes individuais. Apesar de o efeito teórico ser ambíguo, o mesmo resultado, para deságios vencedores, foi encontrado no estudo de Nascimento (2012), para leilões de transmissão de energia no Brasil.

O efeito anticompetitivo dos consórcios pode estar relacionado a algumas possibilidades teóricas e empíricas. Uma delas é a prática anticoncorrencial por parte das empresas, que formariam consórcios para evitar concorrer entre si e, então, partilhar o lucro maior. Consórcios entregariam lances menos competitivos, com menores deságios, para compensar os custos de participação de cada consorciada. Quando empresas com condições de participação isolada formam consórcios, elas eliminam a concorrência que ocorreria entre elas, garantindo maiores chances de vitória para o grupo. No caso da transmissão de energia, apenas 14 das 110 empresas participantes não formaram consórcios. Destaca-se que 16 empresas participaram de 10 formações distintas ou mais de consórcios, muitas delas também com diversas atuações individuais. Essa análise superficial mostra que as formações de consórcios nos leilões de transmissão ocorreram muitas vezes com empresas que também competiam isoladamente.

Tal análise, porém, não é conclusiva em apontar uma conduta anticompetitiva irregular. Em particular, não é possível definir, sem investigações que estão além deste trabalho, se as consorciadas tinham condições de competição isolada, em cada caso. Algumas empresas (como Elecnor, Isolux e Orteng) se uniram a outras, em consórcios, apenas nos primeiros anos, possivelmente como instrumento de entrada nos leilões e depois passaram a competir de forma isolada. Nesse caso, a formação de consórcios pode ter reduzido as barreiras à entrada, sendo, na verdade, favoráveis à competição.

Continuando a investigação acerca dos efeitos da participação dos consórcios, lotes com maior receita máxima permitida estavam associados à maior probabilidade de formação de lances conjuntos, coerente com a perspectiva de restrição de recursos. Como as receitas foram estipuladas pelo governo conforme estimativas de necessidades de investimentos, esses lotes necessitavam de mais recursos financeiros para serem administrados. Por meio de con- 
Tabela 7: Resultados da estimação de diferentes modelos considerando apenas as propostas vencedoras dos leilões de transmissão de energia, de 2000 a 2011

\begin{tabular}{|c|c|c|c|c|c|c|}
\hline \multirow{2}{*}{ Método de Estimação } & \multirow{2}{*}{ (A) } & \multicolumn{2}{|c|}{ (B) } & \multirow{2}{*}{ (C) } & \multicolumn{2}{|c|}{ (D) } \\
\hline & & 1 estágio & 2 estágio & & 1 estágio & 2 estágio \\
\hline Variável Dependente & $\ln$ (lance) & DC & $\ln$ (lance) & desagio & DC & desagio \\
\hline \multicolumn{7}{|l|}{ Variáveis Explicativas } \\
\hline Constante & $\begin{array}{c}-0,1145^{N S} \\
(0,2574)\end{array}$ & $\begin{array}{c}-9,6545^{\text {*** }} \\
(2,4243)\end{array}$ & $\begin{array}{l}0,6160^{*} \\
(0,3734)\end{array}$ & $\begin{array}{c}-0,0382^{N S} \\
(0,1863)\end{array}$ & $\begin{array}{c}-9,4296^{* * *} \\
(2,4071)\end{array}$ & $\begin{array}{c}-0,3318^{N S} \\
(0,2612)\end{array}$ \\
\hline Ln do Número de Competidores & $\begin{array}{c}-0,2616^{* * *} \\
(0,0190)\end{array}$ & $\begin{array}{c}-0,3529^{*} \\
(0,1964)\end{array}$ & $\begin{array}{c}-0,2414^{* * *} \\
(0,0214)\end{array}$ & $\begin{array}{l}0,1903^{* * *} \\
(0,0123)\end{array}$ & $\begin{array}{c}-0,3480^{*} \\
(0,2023)\end{array}$ & $\begin{array}{l}0,1785^{* * *} \\
(0,0140)\end{array}$ \\
\hline Dummy para Consórcio & $\begin{array}{l}0,1191^{* * *} \\
(0,0354)\end{array}$ & & $\begin{array}{l}0,2850^{* * * *} \\
(0,0925)\end{array}$ & $\begin{array}{c}-0,0733^{* * * *} \\
(0,0247)\end{array}$ & & $\begin{array}{c}-0,1704^{* * * *} \\
(0,0632)\end{array}$ \\
\hline Ln da Receita Máxima & $\begin{array}{l}0,9905^{\text {*** }} \\
(0,0162)\end{array}$ & $\begin{array}{l}0,4908^{* * *} \\
(0,1506)\end{array}$ & $\begin{array}{l}0,9578^{* * *} \\
(0,0233)\end{array}$ & $\begin{array}{l}0,0051^{N S} \\
(0,0115)\end{array}$ & $\begin{array}{l}0,4795^{\text {*** }} \\
(0,1498)\end{array}$ & $\begin{array}{l}0,0243^{N S} \\
(0,0164)\end{array}$ \\
\hline Ln da Extensão das linhas & $\begin{array}{l}0,0052^{N S} \\
(0,0096)\end{array}$ & $\begin{array}{l}0,0478^{N S} \\
(0,0656)\end{array}$ & $\begin{array}{l}0,0055^{N S} \\
(0,0092)\end{array}$ & $\begin{array}{c}-0,0042^{N S} \\
(0,0061)\end{array}$ & $\begin{array}{l}0,0541^{N S} \\
(0,0653)\end{array}$ & $\begin{array}{c}-0,0044^{N S} \\
(0,0059)\end{array}$ \\
\hline Dummy para Subsistema & $\begin{array}{c}-0,0934^{* * *} \\
(0,0324)\end{array}$ & $\begin{array}{l}1,1566^{* * *} \\
(0,3370)\end{array}$ & $\begin{array}{l}-0,1379^{* * *} \\
(0,0415)\end{array}$ & $\begin{array}{l}0,0669^{* * *} \\
(0,0214)\end{array}$ & $\begin{array}{l}1,0912^{\text {****}} \\
(0,3532)\end{array}$ & $\begin{array}{l}0,0929^{* * *} \\
(0,0283)\end{array}$ \\
\hline Contrato & \multicolumn{3}{|c|}{$\begin{array}{c}-0,0499^{N S} \\
(0,0310)\end{array}$} & \multicolumn{3}{|c|}{$\begin{array}{c}-0,0494^{N S} \\
(0,0317)\end{array}$} \\
\hline Dummy para Empresa Estrangeira & \multicolumn{3}{|c|}{$\begin{array}{c}-0,1854^{N S} \\
(0,3552)\end{array}$} & \multicolumn{3}{|c|}{$\begin{array}{c}-0,2888^{N S} \\
(0,3461)\end{array}$} \\
\hline Dummy para EPC & \multicolumn{3}{|c|}{$\begin{array}{l}1,0499^{* * * *} \\
(0,2812)\end{array}$} & \multicolumn{3}{|c|}{$\begin{array}{l}1,0485^{* * *} \\
(0,2850)\end{array}$} \\
\hline Número de observações & 148 & \multicolumn{2}{|c|}{148} & 148 & \multicolumn{2}{|c|}{148} \\
\hline
\end{tabular}

\footnotetext{
Regressões por Mínimos Quadrados Ordinários (A e C) e Tratamento de Efeitos (B e D).

Erros-padrão entre parênteses. O sobrescrito NS indica não significância a $10 \%$. * indica significância a $10 \%$.

** indica significância a $5 \% \mathrm{e}^{* * *}$ indica significância a $1 \%$.
}

Fonte: Resultados da pesquisa. 
sórcios, lotes grandes poderiam ser disputados e arrematados com maior facilidade, pois o custo seria divido entre as firmas. Além disso, lotes com maior extensão permitem ganhos maiores com economias de escala, recompensando os custos da formação de consórcios. Esse efeito se intensifica quando se observa que firmas com potenciais ganhos de sinergia estavam associadas aos consórcios vencedores (sinal positivo da variável de localização). Assim, os consórcios poderiam extrair ainda mais ganhos por sinergia, gerenciando a partilha de lucros. Ou, de outra forma, poderiam ser formados quando os empreendimentos envolviam custos maiores. Isso possivelmente explica a relação entre os consórcios e os lances maiores.

Todavia, os deságios dos consórcios foram menores mesmo se tais vantagens existiram. Eles foram menos eficientes que as firmas individuais em suas disputas nos leilões ou as isoladas foram mais otimistas em relação às possibilidades de lucro e entregaram lances menores que os ideais. No entanto, se os leilões híbridos adotados nos leilões de transmissão são eficientes do ponto de vista da informação, como apontado em Dutra \& Menezes (2002), o problema de participantes otimistas, em razões de assimetrias de informação, não deve existir. Logo, não ocorreria formação de consórcios para compartilhar informações e expectativas e os menores deságios devem se originar de ineficiência dos consórcios nos leilões.

No caso dos leilões de transmissão, 145 participantes disputaram os 26 lotes que foram para a segunda etapa dos leilões, que ocorre quando a competição na primeira fase não proporciona lances menores suficientemente distantes do segundo menor lance. Apenas 35 desses participantes eram consórcios, o que pode indicar que as disputas mais acirradas ocorreram, de fato, entre firmas individuais. Por outro lado, 11 desses 35 consórcios venceram os leilões, restando 15 lotes vencidos, na segunda fase, por empresas com lances individuais. Sendo assim, dos 52 lotes vencidos por consórcio, 11 foram vencidos após a realização da segunda etapa, pouco mais de $20 \%$ dos casos. Houve rivalidade nas disputas, embora os deságios dos consórcios tenham sido menores. A razão da menor eficiência dos consórcios em relação às firmas individuais, então, pode ser outra que não conduta ilegal.

Portanto, a menor competitividade dos consórcios, em termos de deságio, deve ser explicada por outros fatores que não o compartilhamento de informações ou condutas ilegais. Apesar de estatisticamente não significativos, consórcios vencedores gerenciavam menos contratos no momento do certame que licitantes individuais, de modo que a restrição de capacidade, que aqui se refere à capacidade de administrar vários contratos, também não foi motivo determinante de sua formação. Observou-se que a presença de empresas de engenharia e construtoras foi positiva e significativa para explicar a probabilidade de formação dos consórcios. Logo, além dos aspectos financeiros associados à receita máxima permitida, a formação dos consórcios parece estar relacionada a aspectos técnicos das concessões, como as necessidades de construção.

Os demais determinantes de lances e deságios apresentaram resultados similares aos da literatura empírica, sendo também coerentes com a teoria. Mantendo as demais variáveis constantes, quanto maior o número de competidores, menores os lances, como em Carlos (2010), e maiores os deságios, como em Nascimento (2012), ambos estudos de leilões de transmissão de energia elétrica no Brasil. O efeito ocorreu como se esperava, pois se trata de uma variável relacionada ao caráter competitivo do processo. Quanto maior o nú- 
mero de competidores, mais acirrada deve ser a disputa, tornando os lances menores e os deságios maiores.

A receita máxima permitida (teto do leilão) e o lance tiveram valores próximos, como esperado pela teoria, que sugere uma convergência de valores quando o objeto leiloado tem componentes comuns, balizados pelo mercado e incorporados no lance máximo permitido. Embora tenha usado investimento, em vez de receita, Carlos (2010) também encontrou relação positiva entre essa variável e o lance vencedor nos leilões de transmissão. O impacto da receita máxima sobre o deságio, por outro lado, foi positivo, mas não foi significativo. Nascimento (2012) também não encontrou efeito significativo do investimento sobre os deságios vencedores nos leilões de transmissão. Com isso, a competição no leilão, avaliada pelo deságio, não dependeu, em termos estatísticos, da receita do edital. O deságio deve estar mais relacionado à expectativa de ganhos que podem ser extraídos da receita do que diretamente à receita. Uma receita elevada não garante lucro elevado se os custos são igualmente altos.

Por fim, embora a extensão quilométrica das linhas não tenha sido significativa em nenhum modelo, a presença de uma concessão no mesmo subsistema do lote leiloado teve impacto competitivo. Deságios maiores e lances menores foram dados quando havia sinergia geográfica. Outros estudos nacionais que consideraram a questão geográfica utilizaram variáveis binárias para cada região do país, encontrando efeitos significativos e positivos para os lances (Carlos 2010) e significativos e positivos apenas para a região Nordeste, na determinação dos deságios vencedores (Nascimento 2012). Rocha et al. (2013) empregaram a questão geográfica apenas como determinante da condição de vencedor e não do lance ou deságio, mas verificaram efeito positivo da existência de sinergia, medida de forma similar à deste trabalho.

Os modelos com os deságios e lances vencedores, apresentados anteriormente, ignoraram o viés de seleção do grupo dos vencedores. A partir desse ponto, serão apresentados os resultados dos modelos com todas as propostas, vencedoras e perdedoras, que não têm esse viés (Tabela 8). Com esses modelos, foi possível observar se os consórcios tiveram, em média, comportamento próximo ao dos consórcios vencedores, permitindo estudar o comportamento de todos os agentes que entregaram proposta, estudando a competição do leilão como um todo e não apenas do resultado final encontrado. Os resultados obtidos foram similares aos dos modelos anteriores.

Assim como nos lances vencedores, a participação das firmas em consórcio teve efeitos anticompetitivos quando todas as propostas foram consideradas (Tabela 8). Na média, os consórcios estavam associados a lances maiores e deságios menores no universo estudado. A correção do viés da endogeneidade tornou esse efeito ainda maior, como pode ser observado pela maior magnitude dos coeficientes da variável de consórcios nas estimativas que corrigiram essa endogeneidade. Embora o efeito teórico da participação de consórcios seja ambíguo, o efeito anticompetitivo está de acordo com o observado para todos os lances vencedores, neste trabalho e em Nascimento (2012). No modelo de Hirota (2006), efeito negativo dos consórcios sobre os deságios também foi encontrado, em um modelo com os lances vencedores e perdedores dos leilões de transmissão estudados. Assim, a hipótese deste trabalho, de que os consórcios neste segmento são menos competitivos, não pode ser rejeitada e está em acordo com o observado nos primeiros estudos nacionais que consideraram essa variável. 
Tabela 8: Resultados da estimação de diferentes modelos considerando todas as propostas dos leilões de transmissão de energia, de 2000 a 2011

\begin{tabular}{|c|c|c|c|c|c|c|}
\hline \multirow{2}{*}{ Método de Estimação } & \multirow{2}{*}{ (A) } & \multicolumn{2}{|c|}{ (B) } & \multirow{2}{*}{ (C) } & \multicolumn{2}{|c|}{ (D) } \\
\hline & & $1^{\circ}$ estágio & $2^{\circ}$ estágio & & $1^{\circ}$ estágio & $2^{\circ}$ estágio \\
\hline Variável Dependente & $\ln ($ lance $)$ & $\mathrm{DC}$ & $\ln$ (lance) & desagio & DC & desagio \\
\hline \multicolumn{7}{|l|}{ Variáveis Explicativas } \\
\hline Constante & $\begin{array}{c}-0,3869^{* * *} \\
(0,1455)\end{array}$ & $\begin{array}{c}-6,4985^{* * *} \\
(1,2606)\end{array}$ & $\begin{array}{l}0,5362^{* * *} \\
(0,1806)\end{array}$ & $\begin{array}{c}-0,2834^{* * *} \\
(0,1045)\end{array}$ & $\begin{array}{c}-6,4985^{* * *} \\
(1,2606)\end{array}$ & $\begin{array}{c}-0,4046^{* * *} \\
(0,1213)\end{array}$ \\
\hline Ln do Número de Competidores & $\begin{array}{l}-0,1261^{* * *} \\
(0,0127)\end{array}$ & $\begin{array}{c}-0,4763^{\text {**** }} \\
(0,1125)\end{array}$ & $\begin{array}{l}-0,1123^{* * *} \\
(0,0175)\end{array}$ & $\begin{array}{l}0,0988^{* * *} \\
(0,0091)\end{array}$ & $\begin{array}{l}-0,4763^{* * *} \\
(0,1125)\end{array}$ & $\begin{array}{l}0,0876^{\text {*** }} \\
(0,0117)\end{array}$ \\
\hline Dummy para Consórcio & $\begin{array}{l}0,0516^{* *} \\
(0,0235)\end{array}$ & & $\begin{array}{l}0,1462^{* * *} \\
(0,0433)\end{array}$ & $\begin{array}{l}-0,0409^{* * *} \\
(0,0138)\end{array}$ & & $\begin{array}{c}-0,1176^{\text {*** }} \\
(0,0291)\end{array}$ \\
\hline Ln da Receita Máxima & $\begin{array}{l}0,9727^{* * *} \\
(0,0092)\end{array}$ & $\begin{array}{l}0,3635^{* * *} \\
(0,0818)\end{array}$ & $\begin{array}{l}0,9617^{* * *} \\
(0,0119)\end{array}$ & $\begin{array}{l}0,0204^{* * *} \\
(0,0067)\end{array}$ & $\begin{array}{l}0,3635^{* * *} \\
(0,0818)\end{array}$ & $\begin{array}{l}0,0294^{\text {*** }} \\
(0,0080)\end{array}$ \\
\hline Ln da Extensão das linhas & $\begin{array}{l}0,0032^{N S} \\
(0,0057)\end{array}$ & $\begin{array}{c}-0,0026^{N S} \\
(0,0480)\end{array}$ & $\begin{array}{l}0,0034^{N S} \\
(0,0061)\end{array}$ & $\begin{array}{c}-0,0024^{N S} \\
(0,0040)\end{array}$ & $\begin{array}{c}-0,0026^{N S} \\
(0,0480)\end{array}$ & $\begin{array}{c}-0,0026^{N S} \\
(0,0041)\end{array}$ \\
\hline Dummy para Subsistema & $\begin{array}{c}-0,0390^{* *} \\
(0,0209)\end{array}$ & $\begin{array}{l}0,8416^{* * * *} \\
(0,1559)\end{array}$ & $\begin{array}{l}-0,0585^{* * * *} \\
(0,0207)\end{array}$ & $\begin{array}{l}0,0343^{* * *} \\
(0,0132)\end{array}$ & $\begin{array}{l}0,8416^{* * * *} \\
(0,1559)\end{array}$ & $\begin{array}{l}0,0501^{\text {**** }} \\
(0,0139)\end{array}$ \\
\hline Contrato & & $\begin{array}{c}-0,1172^{* * * *} \\
(0,0193)\end{array}$ & & & $\begin{array}{l}-0,1172^{* * * *} \\
(0,0193)\end{array}$ & \\
\hline Dummy para Empresa Estrangeira & & $\begin{array}{c}-0,8113^{* * * *} \\
(0,1763)\end{array}$ & & & $\begin{array}{c}-0,8113^{* * * *} \\
(0,1763)\end{array}$ & \\
\hline Dummy para EPC & & $\begin{array}{l}1,1274^{* * *} \\
(0,1416)\end{array}$ & & & $\begin{array}{l}1,1274^{* * *} \\
(0,1416)\end{array}$ & \\
\hline Número de observações & 606 & & & 606 & & \\
\hline
\end{tabular}


As três variáveis instrumentais foram relevantes, mantendo o mesmo sinal daquelas para explicar a probabilidade de formação de consórcios. Os consórcios gerenciavam menos contratos, em média, do que as firmas individuais, indo contra a perspectiva de que eles pudessem ser formados por restrição de capacidade. Contrariando a perspectiva de que consórcios foram formados para compartilhar conhecimentos locais, empresas estrangeiras atuaram mais de forma isolada do que conjunta. Isso pode ter ocorrido pelo fato de elas já estarem no mercado nacional há algum tempo, diminuindo as vantagens de associação que puderam ser inferidas de Estache \& Iimi (2009b). Por outro lado, a participação das empresas construtoras teve efeito positivo sobre a variável. Foi um indício de que a formação dos consórcios estaria associada ao compartilhamento de recursos ou conhecimentos da atividade de construção.

As demais variáveis sobre lances e deságios tiveram os efeitos esperados. $\mathrm{O}$ número de competidores estava negativamente relacionado aos lances dados e positivamente relacionado aos deságios, neste último caso, como em Nascimento (2012). Ao enfrentar um número maior de concorrentes, era esperado que os participantes procurassem, dentro dos limites que garantissem lucro, efetuar lances menores.

A receita máxima, novamente, teve coeficiente indicando estreita proximidade com os lances dados. E, diferentemente do caso apenas com vencedores, ela foi significativa e teve impacto positivo sobre os deságios. A variável investimento foi capaz de explicar os deságios, também com impacto positivo, com 5\% de significância, no estudo de Nascimento (2012). Portanto, a receita máxima estava associada a lances maiores, possivelmente pela convergência das propostas em relação ao teto permitido, mas também estava associada a deságios maiores. Nessa situação, a receita maior poderia estar associada a margens maiores para extração de lucro e, portanto, a deságios maiores.

A extensão quilométrica das linhas de transmissão, assim como quando foram considerados os lances vencedores, não foi significativa em nenhuma especificação. Por outro lado, a variável de sinergia manteve o mesmo resultado, indicando que havia efeitos competitivos quando a disputa ocorria por uma linha localizada em um subsistema em que a proponente já detinha outra concessão. A localização das linhas, medida por binárias de localização, nas quatro regiões do país, não foi significativa para explicar os deságios, em Nascimento (2012), exceto para a região Nordeste, em que deve haver sinergia em favor da Chesf, que disputou e venceu a maior parte dos leilões nesta região.

\section{Conclusões}

Com o desafio de ampliar a capacidade instalada de energia elétrica no Brasil e corrigir problemas enfrentados no setor, foi implantado um processo de reforma estrutural. Esse processo instituiu um modelo baseado na competição nos segmentos de geração e comercialização e no monopólio regulado, com livre acesso, precedido de licitação pública nos segmentos de transmissão e distribuição.

O foco deste trabalho foi verificar o efeito dos consórcios sobre os lances, ou seja, se os lances dados de forma conjunta foram lances maiores (deságios menores) ou menores (deságios maiores) em relação aos das empresas que participaram de forma isolada. Controlando os leilões por número de competidores, receita máxima permitida no leilão, extensão quilométrica das linhas 
e sinergia geográfica, os consórcios forneceram, na média, lances maiores e deságios menores do que as firmas individuais. Avaliando nesses termos, os consórcios foram, portanto, menos competitivos do que as empresas individuais, no período analisado, de 2000 a 2011. Trata-se de um resultado importante, tendo em vista a ambiguidade teórica dos efeitos de participação dos consórcios sobre os leilões. Com isso, os resultados empíricos deste trabalho sugerem que os consórcios foram menos eficientes que as firmas individuais quando disputaram leilões de transmissão de energia no Brasil. O mesmo resultado foi encontrado considerando a decisão de formação de consórcios como endógena e estimando modelos econométricos com variáveis instrumentais e de efeito de tratamento. Nesse caso, o efeito menos competitivo foi ainda mais intenso que no modelo mais simples.

É importante aprofundar a análise dos fatores que levaram os consórcios a realizarem lances menos competitivos. As razões para isso podem indicar melhorias a serem feitas nos desenhos dos próximos leilões, para estimular lances mais competitivos pelos consórcios. É interessante, também, buscar evidências de que as consorciadas nesses leilões teriam condições de executar individualmente os projetos leiloados, indicando potenciais aspectos anticompetitivos do consórcio, ou se os lances conjuntos são formados por outras razões, como ganhos por compartilhamento de recursos e conhecimentos dos serviços de construção. Os resultados obtidos neste trabalho indicam que os consórcios foram principalmente formados em razão de questões técnicas, com parcerias com empresas construtoras e de engenharia.

Embora o método econométrico utilizado tenha permitido a estimação de alguns parâmetros determinantes dos lances e deságios dos leilões, avançando em relação ao problema empírico da endogeneidade na decisão de formação de consórcios, ele deve ser encarado como uma abordagem inicial ao tema. Algumas limitações em relação à estimação feita envolveram a escolha e a determinação das variáveis instrumentais e da proxy para sinergia. Novas pesquisas podem testar outras variáveis instrumentais. Este trabalho também ignorou o impacto das empresas estatais e estrangeiras diretamente sobre os lances e deságios, e o viés de seleção dos vencedores, casos que podem ser incorporados em estudos futuros.

Outro aspecto que pode ser investigado em futuras pesquisas é a externalidade da formação de consórcios na decisão de lances dos outros participantes. Se, ao formar um consórcio, a decisão de lance pelo grupo se diferencia da decisão que seria tomada em caso de participação isolada, os concorrentes naquele leilão corrigirão seus lances para compensar a variação provocada pelo efeito competitivo ou não competitivo do lance conjunto na disputa. É possível, portanto, que essa decisão tenha um impacto sobre o comportamento dos demais licitantes. Além disso, se os lances conjuntos reduzem a competição, parte do excedente que seria do governo é redistribuída para as proponentes.

\section{Referências Bibliográficas}

Albano, G. L., Spagnolo, G. \& Zanza, M. (2008), 'Regulating joint bidding in public procurement.', Journal of Competition Law E Economics 5(2), 335-360. Sep.

ANEEL (2010), Relatório Aneel 10 anos, Brasília, 129 p. 2010, Agência Nacional de Energia Elétrica. 
ANEEL (2012), Acesso em: 05 janeiro, Agência Nacional de Energia Elétrica. URL: http://www.aneel.gov.br

Angrist, J. D. \& Pischke, J. S. (2008), Instrumental variables in action: sometimes you get what you need., In: Mostly harmless econometrics: an empiricist's companion, Princeton, NJ: Princeton University Press.

Cameron, A. C. \& Trivedi, P. K. (2009), Microeconometrics using stata, Statacorp lp, College Station, Texas.

Carlos, A. P. (2010), Strategic behaviour of winning bids in the Brazilian transmission auctions, PhD thesis, Escola de Pós-Graduação em Economia, Fundação Getúlio Vargas. In: Carlos, A. P.. Essays on infrastructure in Brazil.

Cezario, A. P. (2007), Análise de leilões no setor elétrico: energia e transmissão, Master's thesis, Universidade Federal de Pernambuco, Recife, Pernambuco. 116 fls.

De Silva, D. G. (2005), 'Synergies in recurring procurement auctions: an empirical investigation', Economic Inquiry 43(1), 55-66.

De Silva, D., Jeitschko, T. D. \& Kosmopoulou, G. (2005), 'Stochastic synergies in sequential auctions', International Journal of Industrial Organization 23, 183-201.

Dutra, J. C. \& Menezes, F. M. (2002), 'Hybrid auctions', Economic Letters 77, 301-307.

Estache, A. \& Iimi, A. (2009a), 'Enhancing competition in public procurement for sustained growth: applying a double selection model to road procurement auctions', Internacional Journal of Socieal and Human Sciences 3.

Estache, A. \& Iimi, A. (2009b), 'Joint bidding, governance and public procurement costs: a case of road projects', Annals of Public and Cooperative Economics 80(3), 393-429.

Estache, A. \& Iimi, A. (2010), 'Bidder asymmetry in infrastructure procurement: are there any fringe bidders?', Rev Ind Organ 36, 163-187.

Hernández, C. L. G. (2010), Modelo regulatório do setor elétrico no Brasil e sua repercussão jurídica nos contratos de transmissão de energia elétrica, Master's thesis, Escola Politécnica, Universidade de São Paulo.

Hirota, H. H. (2006), O mercado de concessão de transmissão de energia elétrica no Brasil, Master's thesis, Faculdade de Economia Administração e Contabilidade de Ribeirão Preto, Universidade de São Paulo, Ribeirão Preto, SP.

Iimi, A. (2004), '(Anti-)Competitive effect of joint bidding: evidence from ODA procurement auctions', Journal of The Japanese and International Economies 18, 416-439.

IPEA (2010), Série eixos do desenvolvimento brasileiro. setor elétrico: Desafios e oportunidades, Comunicados do ipea $n^{o}$ 51, Instituto de Pesquisa Econômica Aplicada. 
Lauer, O. C. (2006), Avaliação de empresas (valuation): o fluxo de caixa descontado aplicado a empresas transmissoras de energia elétrica., Master's thesis, Centro de Ciências da Administração, Universidade do Estado de Santa Catarina, Florianópolis, SC.

Moura, R. L. d., Canêdo-Pinheiro, M. \& Daitx, F. (2012), 'Determinantes do lance vencedor em leilões de petróleo e gás: avaliando o caso brasileiro', Revista Brasileira de Economia 66(4), 429-444.

Nascimento, R. L. (2012), Análise dos fatores de influência nas propostas ofertadas nos leilões de transmissão de energia elétrica, Master's thesis, Faculdade de Economia, Administração, Contabilidade e Ciência da Informação e Documentação, Universidade de Brasília, Brasília, DF.

OCDE (2008), 'Public procurement: the role of competition authorities in promoting competition'. Organização para Cooperação e Desenvolvimento Econômico.

URL: $h t t p: / / w w w . o e c d . o r g / d a f / c o m p e t i t i o n / c a r t e l s / 39891049 . p d f$

Rezende, L. (2008), 'Econometrics of auctions by least squares', Journal of Applied Econometrics (3), 925-948.

Rocha, K., Moreira, A. \& Limp, R. (2013), 'Determinantes dos altos deságios nos leilões de transmissão de energia elétrica no Brasil entre 1999 - 2010', Revista Brasileira de Economia 67(2), 261-274.

Serrato, E. (2008), Electricity transmission sector in Brazil - analysis of the auctions' results and the public and private firm's costs, Master's thesis, The George Washington University School of Business and Public Management Institute of Brazilian Business and Public Management Issues, WashingtonDC. 